\title{
RP-HPLC Method Development and Validation for Estimation of Naftidrofuryl Oxalate Using Box- Behnken Design
}

\author{
Krishna R Gupta*, Anita R Pounikar and Milind J Umekar \\ Department of Pharmaceutical Chemistry, Smt Kishoritai Bhoyar College of Pharmacy, India
}

*Corresponding author: Krishna R Gupta, Professor Department of Pharmaceutical Chemistry, Smt Kishoritai Bhoyar

College of Pharmacy, Kamptee, Nagpur (MS), India

ARTICLE INFO

Received: 幽 November 26, 2021

Published: 櫘December 07, 2021

Citation: Krishna R Gupta, Anita R Pounikar, Milind J Umekar. RP-HPLC Method Development and Validation for Estimation of Naftidrofuryl Oxalate Using Box-Behnken Design. Biomed J Sci \& Tech Res 40(3)-2021. BJSTR. MS.ID.006447.

Keywords: Naftidrofuryl Oxalate; Box-Behnken Design; RP-HPLC Method Development; Validation

\begin{abstract}
A simple, rapid, precise, sensitive, economical, robust and QbD based RP -HPLC method has been developed for Naftidrofuryl oxalate and validated as per ICH guidelines. The response surface methodology employed with a 3-factor, 3- level Box-Behnken statistical design and used to facilitate method development and optimization. The response surface methodology and multiple response optimizations utilizing a polynomial equation were used to select suitable mobile phase combination. The independent variables studied were the Organic phase $\left(\mathrm{X}_{1}\right)$, Aqueous phase $(\mathrm{X} 2)$ and $\left(\mathrm{X}_{3}\right)$ and the responses was Retention time $\left(\mathrm{Y}_{1}\right)$, Resolution $\left(\mathrm{Y}_{2}\right)$ and Tailing factor $\left(\mathrm{Y}_{3}\right)$. Chromatographic separation was achieved on Zodiac C18 column $(100 \mathrm{~mm} \times 4.6$, $3 \mu \mathrm{m}$ ), using optimized mobile phase Acetonitrile and pH-7 Tetrabutyl-ammonium buffer solution (90:10), at $282 \mathrm{~nm}$. The flow rate and injection volume were $1.0 \mathrm{~mL}-1$ min and $20 \mu \mathrm{L}$, respectively. Analysis of variance (ANOVA) confirmed that the three factors were significant. The method was validated for linearity, system suitability, recovery (accuracy), precision, robustness, ruggedness, limit of quantitation (LOD) and detection (LOQ) as per the ICH guidelines. The precision, ruggedness and robustness values were also within the prescribed limits. Calibrations curves were linear (r2= $0.997)$ at the concentration range of 10 to $50 \mu \mathrm{g} / \mathrm{mL}$. LOD and LOQ values were $12.914 \mu \mathrm{g} / \mathrm{mL}$ and $39.132 \mu \mathrm{g} / \mathrm{mL}$ respectively. The proposed method was successfully developed by applying QBD based concept and proposed method can be used for routine analysis of Naftidrofuryl oxalate in quality control laboratories.
\end{abstract}

\section{Introduction}

Naftidrofuryl, chemically it is a (RS)-2-(diethylamino) ethyl-3(1-naphthyl)- 2-(tetrahydro furan-2-ylmethyl) propanoate and it is available in the form of oxalic acid. It is also known as nafronyl, INN, NF, NAFTI or as the oxalate salt nafronyl oxalate [1]. The chemical formula of Naftidrofuryl oxalate is (C26H35NO7) with molecular weight is 473.56 as shown in Figure 1 [2]. Naftidrofuryl oxalate shows smooth muscle relaxation, increases cerebral blood flow as well as peripheral blood flow, cerebral adenosine triphosphate concentrations and glucose utilization properties attracts its pharmacological applications in the treatment of senile brain diseases a vasodilator. Therefore, it is widely used in the treatment of peripheral and cerebral vascular disorders $[3,4]$.

The British Pharmacopoeia (BP) describes a potentiometric non-aqueous titration and high-performance liquid chromatography (HPLC) methods for the assay of NF in bulk form and capsules, respectively [5,6]. The literature survey reveals that few analytical methods have been reported for the determination of Naftidrofuryl oxalate in biological fluids and/or 
pharmaceutical preparations by using high-performance liquid chromatography [7], high- performance liquid chromatography with fluorescence detection [8,9], RP-HPLC fluorimetry [10], phosphorimetry [11], phosphorescence [12,13], Phosphorimetric determination [14], ion-selective membrane electrodes method [15], spectrophotometric analysis [16], Spectrophotometric, spectrofluorimetric and voltammetric analysis [17] and Stability Indicating Methods [18] were reported till date. Naftidrofuryl oxalate molecule,is composed with the ester linkage associates naphtha- lene propionic acid and diethylaminoethyl moieties and easily hydrolysis in aqueous solutions by either acid-or basecatalyzed reaction to form 3-(1-naphthyl)-2-tetrahydro furfuryl propionic acid, (Naftidrofurylacid, NFA) and diethylaminoethanol. Figure 2 shows the degradation reaction pathway of Naftidrofuryl oxalate. NFA is the metabolite of naftidrofuryl oxalate has been found in human plasma $[4,19]$.

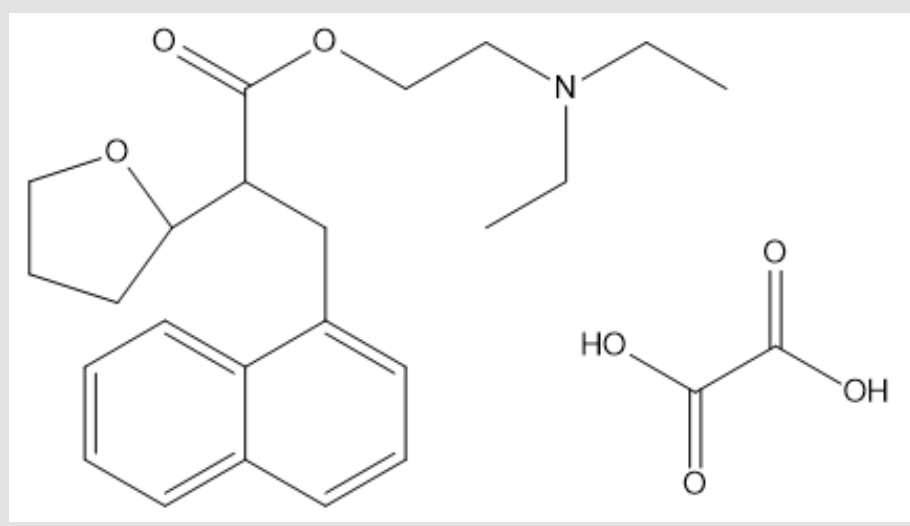

Figure 1: Structure of Naftriduroyl Oxalate.

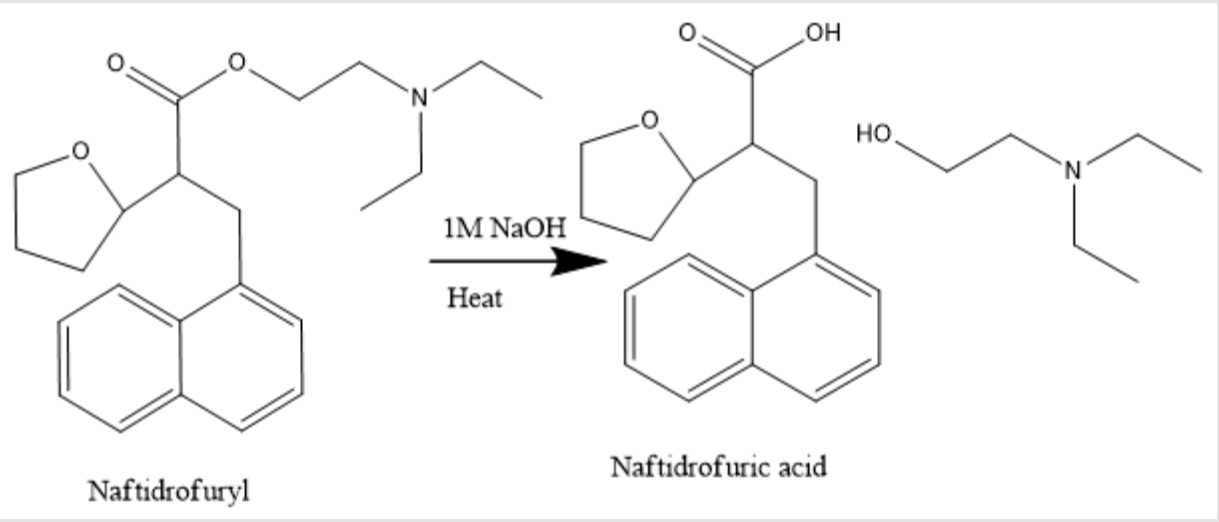

Figure 2: Hydrolysis rection of Naftidrofuryl.

It is desirable to develop a simple, precise, robust and fast procedure that could be applied in quality control laboratories for the selective determination of Naftidrofuryl oxalate in the pharmaceutical product. The developed method can be utilized for the determination of drug content in its pharmaceutical dosage form is also demonstrated. For this we select QbD based RP-HPLC method development. In a olden days, one factor at a time (OFAT) and keeping the others fixed as a traditional approach used for optimization of HPLC methods, results in achievement of narrow robust, precise and rugged behavior of the method for instrumental variables used in method development phase. This approach may cause high risk in method failure and always requires revalidation protocol after method transfer or alternative method development used to ensure the consequences; thereby it has been increasing the cost of the method, regulatory burden, recall of drugs and batch failure cost [20,21].

Nowadays, QbD is used as a systematic, scientifically based, holistic and proactive approach and powerful tool for chromatographic method development. In this approach we can understand process parameters that influence chromatographic separation by determination of critical ones, their positive or negative effect on the selected responses, and the multidimensional interaction between them. In addition, the change in variable of QbD facilitates the purposeful variables changes will gives desired response and suggests the optimal solution with variables value that best gives the maximum, minimum or target response, while at the same time it finds the spot with the minimum error transmitted 
to the responses. So, this should represent robust process conditions that not affected by slight variations in factor settings. It also suggests a mathematical model that relates the response and the experimental variables, thus allowing response prediction with minimum error transmitted to the response [22-26].

Application of DoE principles facilitates understanding of multiple method parameters and variables that tend to affect CMAs, while unravelling the prevalence of (any) interactions and reducing intricacies. For the successful execution of DoE study, the knowledge of response variables or CMAs, CMVs, their ranges, and best fitting of the mathematical model(s) is mandatory. DoE-based Response Surface Methodology (RSM) is helpful in systematic development of analytical methods involving significant nonlinearity between CMV-CMA relationship(s) using diverse experimental designs like Factorial design, Central Composite design, Box Behnken design, Optimal design, etc. The experimental designs help in mapping the responses on the basis of the studied objective(s), CMAs being explored, at high (coded as +1 ), medium (coded as 0 ), or low (coded as -1) levels of CMVs. It tends to unearth the mechanistic understanding of CMVs and CMAs relationship, and associated interactions among them. Various 3D and 2D-plots like response surface plots, contour plots, perturbation charts, linear correlation plots, outlier plot and Box-Cox plot are some of the key pictorial/ graphical tools of the experimental designs useful for the purpose $[27,31]$.

The literature survey reveals that the BBD was one of the design strategies employed for selection and optimization of mobile phase during chromatographic analysis. The BBD is different from all screening designs as it contains combinations or midpoints of edges of the process space and at the center, i.e., variables at their highest or lowest levels, so that the designs will avoid all factors which affects method. These designs are useful in avoiding experiments performed under extreme conditions as these may give unsatisfactory results [32-34]. In the RSM design, Box-Behnken statistical design is an independent, rotatable or nearly rotatable, quadratic design, requires fewer experimental runs and less time and thus provides a far more effective and costeffective technique than the conventional processes of formulating and optimization of dosage forms [35].

Literature survey revealed that there is no previously reported analytical QbD based RP- HPLC method for NF. Thus, the main goal of this work was to establish a precise, accurate and sensitive $\mathrm{QbD}$ based RP-HPLC method for NF using RSM and Multiple responses optimization utilizing quadratic polynomial equation. Screening of the critical factors was achieved using BBD, the independent variables for the present study was Organic phase $\left(\mathrm{X}_{1}\right)$, Aqueous phase $\left(\mathrm{X}_{2}\right)$ and $\left(\mathrm{X}_{3}\right)$ and the responses was Retention time $\left(\mathrm{Y}_{1}\right)$,
Resolution $\left(\mathrm{Y}_{2}\right)$ and Tailing factor $\left(\mathrm{Y}_{3}\right)$. The developed method was validated for linearity, system suitability, recovery (accuracy), precision, robustness, ruggedness, limits of quantitation (LOD) and detection (LOQ) as per the ICH guidelines [36,37].

\section{Experimental}

\section{Materials}

Naftidrofuryl oxalate was obtained as a gift sample from Zim Lab, Nagpur, India. All the chemicals such as Methanol and Acetonitrile (HPLC grade), Ammonium acetate, Tetra butyl ammonium hydroxide and Concentrated Nitric acid (AR grade), procured from Merk life science private limited Mumbai and Final limited Ahemdabad.

Instrumentation and Chromatographic Conditions: HPLC analysis was carried out using Shimadzu HPLC series 1100. Separation was carried out on Zodiac column (C18 100mm×4.6 I.D., $3 \mu \mathrm{m}$ particle size column), Detection was achieved using SPD-10UV detector and LC 10 ADVP-pumps connected to a hp computer. The mobile phase was prepared by mixing Tetrabutyl-ammonium buffer and Acetonitrile (adjusted to $\mathrm{pH} 7$ with concentrated Nitric acid) in a ratio of $10: 90 \mathrm{v} / \mathrm{v}$, then filtered through $0.45 \mu \mathrm{m}$ membrane filter (Millipore, Milford, MA, USA). The injection volume was $20 \mu \mathrm{L}$ with a flow rate of $1.0 \mathrm{~mL} / \mathrm{min}$ and $\mathrm{UV}$ detection at $282 \mathrm{~nm}$. The wavelength of maximum absorbance was detected by UV-Visible spectrometer (double beam), Shimadzu UV-1700 model and wavelength scanning range was 200-400nm was exercised using UV probe software. For applying quality by design Design Expert $₫ 11.0$ - trial version software was used.

Preparation of Standard Solutions: A stock solution of 1000 $\mu \mathrm{g} / \mathrm{mL}$ was prepared by dissolving $10 \mathrm{mg}$ of Naftidrofuryl oxalate standard in $10 \mathrm{~mL}$ of a mixture Tetrabutyl- ammonium buffer and Acetonitrile (adjusted to $\mathrm{pH} 7$ with Concentrated Nitric acid) in a ratio of 10:90 v/v. Standard solutions were prepared by further dilution of stock solution with the same solvent to get $30 \mu \mathrm{g} / \mathrm{mL}$.

\section{Experimental Design}

Scouting Step: This step included some trials of the mobile phase that gives an acceptable well resolved chromatographic peak of analyte. At the beginning, different mobile phases containing Tetrabutyl ammonium buffer and Acetonitrile as the aqueous/ organic part of the mobile phase were tried. In addition, change in ratio of Tetrabutyl- ammonium buffer and Acetonitrile were tested. Finally, the variables that may affect the selected CQA were selected.

Screening Design: In the present study, 3-factor, 3-level BoxBehnken statistical design was used to evaluate the effect of selected responses, to characterize the drug contents and to optimize the developed method. BBD is efficacious for exploration of quadratic 
response surfaces, mathematical screening and thus helping to optimize the process by using a small number of experimental runs. The dependent and independent variables selected are given
Table 1 along with their low, medium and high levels, which were selected based on the results from preliminary experimentation. The observed responses are given in Table 2 .

Table 1: Variables in Box Behnken Design.

\begin{tabular}{|c|c|c|c|}
\hline \multirow{2}{*}{ Variable in Design } & \multicolumn{2}{|c|}{ Levels used, actual (Coded) } \\
\cline { 2 - 4 } & Low (-1) & Medium (0) & High (+1) \\
\hline $\mathrm{X}_{1}=$ Organic phase (\%) & 85 & 90 & 95 \\
\hline $\mathrm{X}_{2}=$ Aqueous phase (\%) & 5 & 10 & 15 \\
\hline $\mathrm{X}_{3}=$ flow rate (ml/min) & 0.8 & 1 & 1.2 \\
\hline
\end{tabular}

Table 2: The observed responses in Box-Behnken Design for Naftidrofuryl Oxalate.

\begin{tabular}{|c|c|c|c|c|c|c|}
\hline \multirow{2}{*}{ Experiment (Run) } & \multicolumn{3}{|c|}{ Independent variables } & \multicolumn{3}{|c|}{ Dependent variables } \\
\hline & $\mathrm{X}_{1}(\%)$ & $\mathrm{X}_{2}(\%)$ & $\mathrm{X}_{3}(\mathrm{ml} / \mathrm{min})$ & $Y_{1}(\min )$ & $\mathrm{Y}_{2}(\mathrm{RS})$ & $\mathrm{Y}_{3}(\mathrm{TF})$ \\
\hline BB 1 & 90 & 10 & 1 & 2.614 & 5.751 & 1.117 \\
\hline BB 2 & 85 & 10 & 1.2 & 2.165 & 7.068 & 1.523 \\
\hline BB 3 & 95 & 15 & 1 & 2.645 & 6.307 & 1.619 \\
\hline BB 4 & 90 & 15 & 0.8 & 3.529 & 7.978 & 1.527 \\
\hline BB 5 & 90 & 5 & 0.8 & 3.279 & 7.37 & 1.412 \\
\hline BB 6 & 90 & 5 & 1.2 & 2.238 & 5.509 & 1.277 \\
\hline BB 7 & 90 & 10 & 1 & 2.607 & 5.596 & 1.157 \\
\hline BB 8 & 95 & 10 & 1.2 & 2.181 & 6.114 & 1.653 \\
\hline BB 9 & 85 & 10 & 0.8 & 2.252 & 7.628 & 1.46 \\
\hline BB 10 & 90 & 10 & 1 & 2.558 & 5.049 & 1.174 \\
\hline BB 11 & 85 & 5 & 1 & 2.182 & 7.522 & 1.528 \\
\hline BB 12 & 85 & 15 & 1 & 2.595 & 8.752 & 1.45 \\
\hline BB 13 & 95 & 10 & 0.8 & 3.643 & 5.508 & 1.489 \\
\hline BB 14 & 90 & 15 & 1.2 & 2.165 & 7.457 & 1.243 \\
\hline BB 15 & 90 & 10 & 1 & 2.559 & 5.529 & 1.131 \\
\hline BB 16 & 90 & 10 & 1 & 2.607 & 5.046 & 1.129 \\
\hline BB 17 & 95 & 5 & 1 & 2.861 & 5.928 & 1.523 \\
\hline
\end{tabular}

Note: *Variables $\mathrm{X}=$ Organic phase $\left(\mathrm{X}_{1}\right)$, Aqueous phase $\left(\mathrm{X}_{2}\right)$ and Flow rate $\left(\mathrm{X}_{3}\right)$. Responses $\mathrm{Y}=$ Retention Time $\left(\mathrm{Y}_{1}\right)$, Resolution $\left(\mathrm{Y}_{2}\right)$ and Tailing factor $\left(\mathrm{Y}_{3}\right)$.

BBD a also used to optimize and evaluate the main effects, interaction effects and quadratic effects of the independent factors on the dependent factors as 3-factor, 3-level Box-Behnken statistical design suitable for exploring quadratic response surfaces and constructing second order polynomial model with Design Expert ${ }^{\circledast}$ 11.0 - Trial Version software. The nonlinear computer-generated quadratic model is given as

$Y_{0}=b_{0}+b_{1} X_{1}+b_{2} X_{2}+b_{3} X_{3}+b_{12} X_{1} X_{2}+b_{13} X_{1} X_{3}+b_{23} X_{2} X_{3}+b_{11} X_{2}+b_{22} X_{2}+b_{33} X_{2}$

where $\mathrm{Y}_{\mathrm{o}}$ is the dependent variable; $\mathrm{b}_{\mathrm{o}}$ is an intercept; $\mathrm{b}_{1}-\mathrm{b}_{33}$ are regression coefficients computed from the observed experimental values of $Y$; and $X_{1}-X_{3}$ are the coded levels of independent variables. The terms $X_{1}, X_{2}$ and $X_{i}(i=1,2$ or3) represent the interaction and quadratic terms, respectively
Optimization Data Analysis: The responses Retention Time $\left(\mathrm{Y}_{1}\right)$, Resolution $\left(\mathrm{Y}_{2}\right)$ and Tailing factor $\left(\mathrm{Y}_{3}\right)$ of were treated by Design-Expert software design such as BBD which consist of three components include linear, quadratic and special cubic models. The best fitting mathematical model such as ANOVA method and Good fit evaluation were selected based on the comparisons of several statistical parameters including the coefficient of variation (C.V.), the multiple correlation coefficient $\left(\mathrm{R}^{2}\right)$, adjusted multiple correlation coefficient (adjusted $\mathrm{R}^{2}$ ); and the predicted residual sum of square (PRESS), proved by Design-Expert software. Among them, PRESS indicates how well the model fits the data, and for the chosen model it should be small relative to the other models under consideration.Also various 3-D response surface graphs and counter plots were provided by the Design- Expert software. 
By intensive grid search performed over the whole experimental region, the optimum checkpoint mobile phase composition was selected to validate the chosen experimental domain and polynomial equations. The optimized checkpoint mobile phase composition was prepared and evaluated for various response properties. The resultant experimental values of the responses were quantitatively compared with that of the predicted values. Also, linear regression plots between actual and predicted values of the responses were produced using MS- Excel version 2019.

Validation: The method was validated in accordance with the International Conference on Harmonization (ICH) requirements [37], which involved linearity, system suitability, recovery (accuracy), precision, robustness, ruggedness, limits of quantitation (LOD) and detection (LOQ).

Linearity, LOD, and LOQ: The linearity of the method was assessed at five concentrations within the appropriate range. To construct the calibration curves the peak areas were plotted against concentrations. For an analyte in a sample, LOD is the lowest concentration which can be detected, not quantified. On the other hand, LOQ is the lowest concentration was calculated.

System Suitability: The system suitability parameters area, retention time, tailing factor, theoretical plates and resolution were calculated by injecting standard Naftidrofuryl oxalate solution.

Accuracy: The accuracy of the proposed method was indicated by $\%$ recovery of the five different concentrations of Naftidrofuryl oxalate.

Robustness: In addition to identifying the design space that represents a robustness zone, the insensitivity of the proposed method to small changes in the optimized conditions such as deliberate changes in the method were done i.e., Change in flow rate $(1.0 \pm 0.2 \mathrm{~mL} / \mathrm{min})$, change in mobile phase concentration (organic portion of $90 \% \pm 5 \%$ ), change in column and change in $\mathrm{pH}$ of Buffer solution $(7.0 \pm 0.2 \mathrm{pH})$ in mobile phase.

Ruggedness: The studies were carried out for two different parameters i.e., Days (Intraday and Interday) and Analyst to Analyst variation. Single concentration level was selected and analyzed as described before three times within the same day (intra-day precision) by different analysts, and on successive three days (inter-day precision). The \% RSD was calculated as a measure for method precision.

\section{Results and Discussion}

\section{Scouting Step}

An isocratic mobile phase consisting of Tetrabutyl- ammonium buffer $20 \%$ and acetonitrile $80 \%$ was applied at the beginning. This mobile phase gave strong tailing and no well resolved peak shape. When \% of Tetrabutyl- ammonium buffer was increased and \% of acetonitrile reduced, tailing increased strongly. Then we reduced $\%$ of tetrabutyl-ammonium buffer and \% of acetonitrile increased in order to have better resolution. In this case, good peaks shape was obtained. In this step, three factors were chosen: the \% aqueous part of the mobile phase, $\%$ of organic phase and flow rate.

\section{Screening with BBD}

The significance of model so obtained can be evaluated by two ways i.e. ANOVA method and Good fit evaluation. ANOVA is a statistical method based on F-test to estimate the significance of model. It involves subdividing total variation into variation due to Residual error, Main effects and Interactions.

\section{ANOVA Technique}

The ANOVA (one-way Analysis of Variance) is used to ensure about the significant differences between the means of three or more independent groups. The results of ANOVA of Variance for Retention time $\left(\mathrm{Y}_{1}\right)$, Resolution $\left(\mathrm{Y}_{2}\right)$ and Tailing factor $\left(\mathrm{Y}_{3}\right)$ shown in Table 3. The Model F-value of Retention time $\left(\mathrm{Y}_{1}\right)$, Resolution $\left(\mathrm{Y}_{2}\right)$ and Tailing factor $\left(\mathrm{Y}_{3}\right)$ was found to be 16.69, 10.72 and 7.11 respectively and it implies that the model is significant. There is only a $0.01 \%$ chance that an F-value this large could occur due to noise. P-values less than 0.0500 indicate model terms such as $-\mathrm{A}$, C, AC in Retention time(Y1), - A, B, $\mathrm{A}^{2}, \mathrm{~B}^{2}, \mathrm{C}^{2}$ in Resolution ( $\mathrm{Y}_{2}$ ) and $-A^{2}, B^{2}, C^{2}$ in Tailing factor $\left(Y_{3}\right)$ are significant model terms. Values greater than 0.1000 indicate the model terms are not significant. If there are many insignificant model terms. The Lack of Fit F-value of 66.01 and 32.46 in Retention time $\left(\mathrm{Y}_{1}\right)$ and Tailing factor $\left(\mathrm{Y}_{3}\right)$ respectively implies that the Lack of Fit is significant. Whereas in the Resolution $\left(\mathrm{Y}_{2}\right)$, Lack of Fit F-value of 3.02 implies the Lack of Fit is not significant relative to the pure error. There is a $15.69 \%$ chance that a Lack of Fit F-value this large could occur due to noise. The average values obtained from the software are given in Table 4.

Table 3: ANOVA results of the Box Behnken design for response surface quadratic model.

\begin{tabular}{|c|c|c|c|c|c|c|}
\hline \multirow{2}{*}{ Source } & \multicolumn{2}{|c|}{ Retention time(Y1) } & \multicolumn{2}{|c|}{ Resolution (Y2) } & \multicolumn{2}{|c|}{ Tailing factor (Y3) } \\
\hline & F-value & p-value & F-value & p-value & F-value & p-value \\
\hline Model & 16.69 & 0.0001 & 10.72 & 0.003 & 7.11 & 0.009 \\
\hline A-\% org phase & 18.19 & 0.002 & 31.8 & 0.001 & 1.67 & 0.238 \\
\hline B-\% Aq phase & 0.558 & 0.472 & 10.9 & 0.0131 & 0.156 & 0.704 \\
\hline C-flowrate & 62.34 & $<0.0001$ & 3.43 & 0.106 & 0.588 & 0.468 \\
\hline
\end{tabular}




\begin{tabular}{|c|c|c|c|c|c|c|}
\hline $\mathrm{AB}$ & 3.16 & 0.106 & 0.91 & 0.372 & 0.966 & 0.358 \\
\hline $\mathrm{AC}$ & 15.08 & 0.003 & 1.71 & 0.232 & 0.326 & 0.586 \\
\hline $\mathrm{BC}$ & 0.832 & 0.383 & 2.26 & 0.177 & 0.709 & 0.428 \\
\hline $\mathrm{A}^{2}$ & & & 8.06 & 0.025 & 0.001 & 0.62 \\
\hline $\mathrm{B}^{2}$ & & & 26.37 & 0.035 & 6.77 & 0.037 \\
\hline $\mathrm{C}^{2}$ & & & 6.84 & 0.157 & 32.46 & 0.003 \\
\hline Lack of Fit & 66.01 & 0.0006 & 3.02 & \multicolumn{2}{c|}{ Nignificant } \\
\hline Result & \multicolumn{2}{|c|}{ Significant } \\
\hline
\end{tabular}

Table 4: Table for average values obtained from the software.

\begin{tabular}{|c|c|c|c|}
\hline Source & Retention time $\left(\mathbf{Y}_{\mathbf{1}}\right)$ & Resolution $\left(\mathbf{Y}_{\mathbf{2}}\right)$ & Tailing factor $\left(\mathbf{Y}_{\mathbf{3}}\right)$ \\
\hline Std. Dev. & 0.18 & 0.45 & 0.089 \\
\hline Adj R-Squared & 0.8548 & 0.8454 & 0.7745 \\
\hline Pred R-Squared & 0.5462 & 0.217 & -0.522 \\
\hline Adeq Precision & 14.752 & 9.811 & 7.14 \\
\hline
\end{tabular}

\section{Main Effects (Lack of Fit)}

The Lack of Fit is one of the components of partition of the sum of squares in an ANOVA which can tell that that purpose model is fit or not. The results of Lack of Fit Test and Model Summary Statistics of Retention time $\left(\mathrm{Y}_{1}\right)$, Resolution $\left(\mathrm{Y}_{2}\right)$ and Tailing factor $\left(\mathrm{Y}_{3}\right)$ showed in Table 5.

Table 5: Model Summary Statistics for Lack of Fit Test.

\section{Interactions}

The equation in terms of actual factors can be used to make predictions about the response for given levels of each factors are given in Table 6.

\begin{tabular}{|c|c|c|c|c|c|c|}
\hline \multicolumn{7}{|c|}{ Retention time $\left(Y_{1}\right)$} \\
\hline Source & Std. Dev. & $\mathbf{R}^{2}$ & Adjusted $\mathrm{R}^{2}$ & Predicted $\mathrm{R}^{2}$ & PRESS & Remark \\
\hline Linear & 0.265 & 0.736 & 0.675 & 0.451 & 1.9 & - \\
\hline $2 \mathrm{FI}$ & 0.177 & 0.909 & 0.855 & 0.546 & 1.57 & - \\
\hline Quadratic & 0.148 & 0.956 & 0.899 & 0.308 & 2.39 & Suggested \\
\hline Cubic & 0.028 & 0.999 & 0.996 & & & - \\
\hline \multicolumn{7}{|c|}{ Resolution $\left(\mathrm{Y}_{2}\right)$} \\
\hline Source & Std. Dev. & $\mathrm{R}^{2}$ & Adjusted $\mathrm{R}^{2}$ & Predicted $\mathrm{R}^{2}$ & PRESS & Remark \\
\hline Linear & 0.937 & 0.446 & 0.318 & 0.135 & 17.81 & - \\
\hline $2 \mathrm{FI}$ & 1.02 & 0.493 & 0.189 & -0.38 & 28.39 & - \\
\hline Quadratic & 0.446 & 0.932 & 0.845 & 0.217 & 16.11 & Suggested \\
\hline Cubic & 0.327 & 0.979 & 0.917 & & & - \\
\hline \multicolumn{7}{|c|}{ Tailing factor $\left(\mathrm{Y}_{3}\right)$} \\
\hline Source & Std. Dev. & $\mathrm{R}^{2}$ & Adjusted $\mathrm{R}^{2}$ & Predicted $\mathrm{R}^{2}$ & PRESS & Remark \\
\hline Linear & 0.203 & 0.034 & -0.189 & -0.537 & 0.854 & - \\
\hline $2 \mathrm{FI}$ & 0.228 & 0.062 & -0.501 & -1.802 & 1.56 & - \\
\hline Quadratic & 0.089 & 0.901 & 0.775 & -0.522 & 0.846 & Suggested \\
\hline Cubic & 0.023 & 0.996 & 0.984 & & & - \\
\hline
\end{tabular}

Table 6: Table for final Equation in Terms of Actual Factors.

\begin{tabular}{|c|c|c|c|}
\hline \multicolumn{4}{|c|}{ Final Equation in Terms of Actual Factors } \\
\hline Factors & Retention time $\left(\mathbf{Y}_{\mathbf{1}}\right)$ & Resolution $\left(\mathbf{Y}_{\mathbf{2}}\right)$ & Tailing factor $\left(\mathbf{Y}_{\mathbf{3}}\right)$ \\
\hline Model & -37.206 & 262.33 & 97.119 \\
\hline A (\% org phase) & 0.46 & -4.827 & -2.032 \\
\hline
\end{tabular}




\begin{tabular}{|c|c|c|c|}
\hline B (\% Aq phase) & 0.656 & -0.358 & -0.206 \\
\hline C (flowrate) & 29.273 & -59.459 & -7.63 \\
\hline AB & -0.006 & -0.009 & 0.002 \\
\hline AC & -0.344 & 0.292 & 0.025 \\
\hline BC & -0.081 & 0.335 & -0.037 \\
\hline$A^{2}$ & & 0.025 & 0.011 \\
\hline B $^{2}$ & & 0.045 & 0.004 \\
\hline C $^{2}$ & 2FI & Quadratic & 2.805 \\
\hline Model & & Quadratic \\
\hline
\end{tabular}

\section{Contour Plots and Response Surface Analysis}
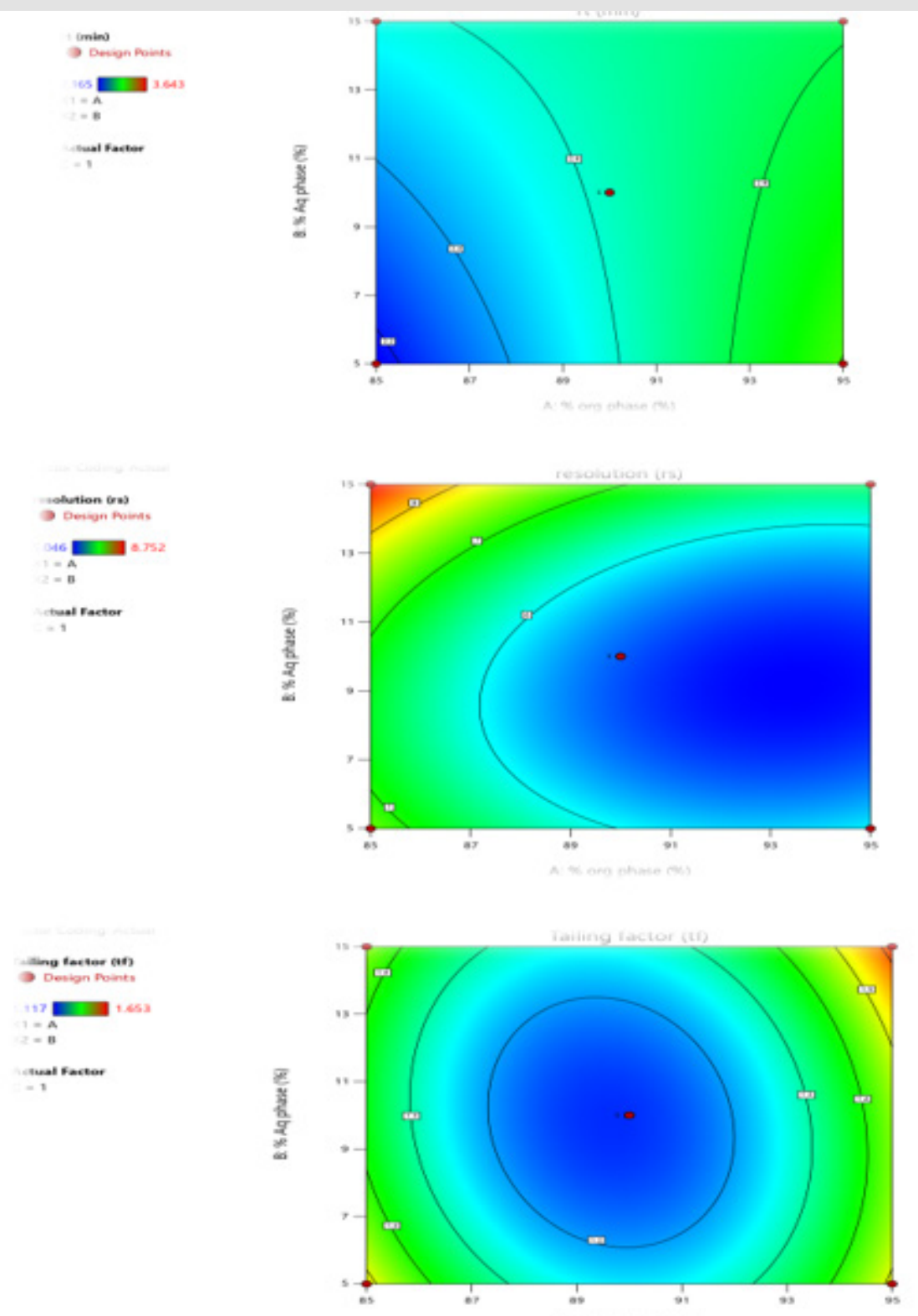

Figure 3:

a. Counter Plot for Response Retention Time.

b. Counter Plot for Response Resolution.

c. Counter Plot for Response Tailing factor. 
The graphical optimization was another tool used to specify the design space or sweet spot where the desired CQAs meet. The goal of graphical optimization was to maximize both responses after speci- fying their lowest acceptable limits. 3D plot showed the interaction effect of the critical factors. Two-dimensional contour plot of Retention time $\left(\mathrm{Y}_{1}\right)$, Resolution $\left(\mathrm{Y}_{2}\right)$ and Tailing factor $\left(\mathrm{Y}_{3}\right)$ shown in Figures 3a-3c and three- dimensional response surface plot are presented in Figures $4 a-4 c$ which is very useful to study the interaction effects of the factors on the responses. These types of plots show the effects of two factors on the response at a time.
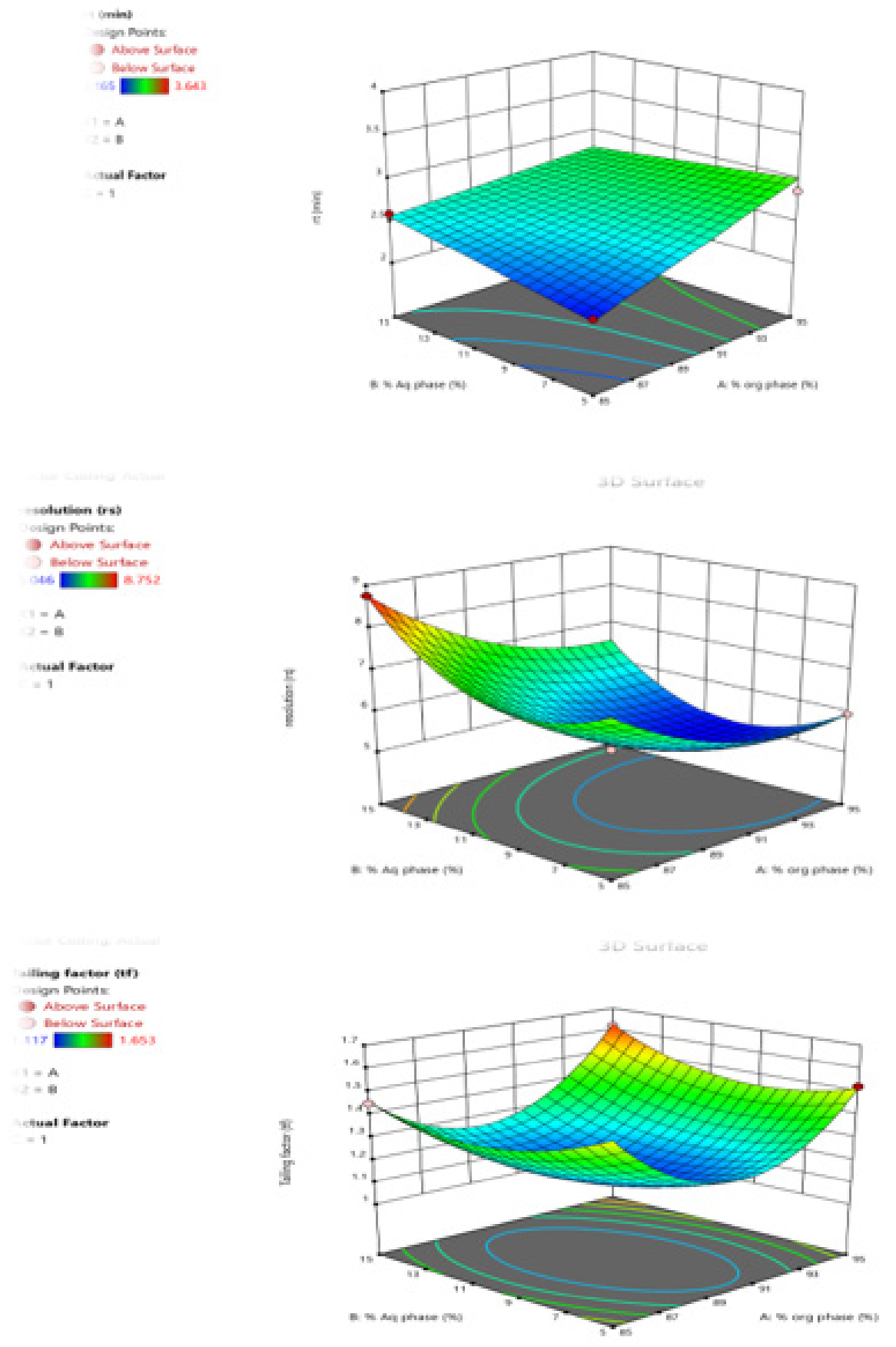

Figure 4:

a. Surface Response Curve for Response Retention Time.

b. Surface Response Curve for Response Resolution.

c. Surface Response Curve for Response Tailing factor. 


\section{Validation}

\section{Linearity, LOD, and LOQ}

Linearity study was performed on Naftidrofuryl oxalate under the optimized chromatographic conditions; a good linearity was obtained between the peak areas and the concentration ranging from 10 to $50 \mu \mathrm{g} / \mathrm{mL}$. The observations are shown in Table 7, from the data, a plot concentration $(\mu \mathrm{g} / \mathrm{mL}$ ) Vs Area Under Curve (AUC) was constructed for the Naftidrofuryl oxalate (Figure 5). The study of graphical plots represents correlation coefficient of Naftidrofuryl oxalate was found to be 0.997 .

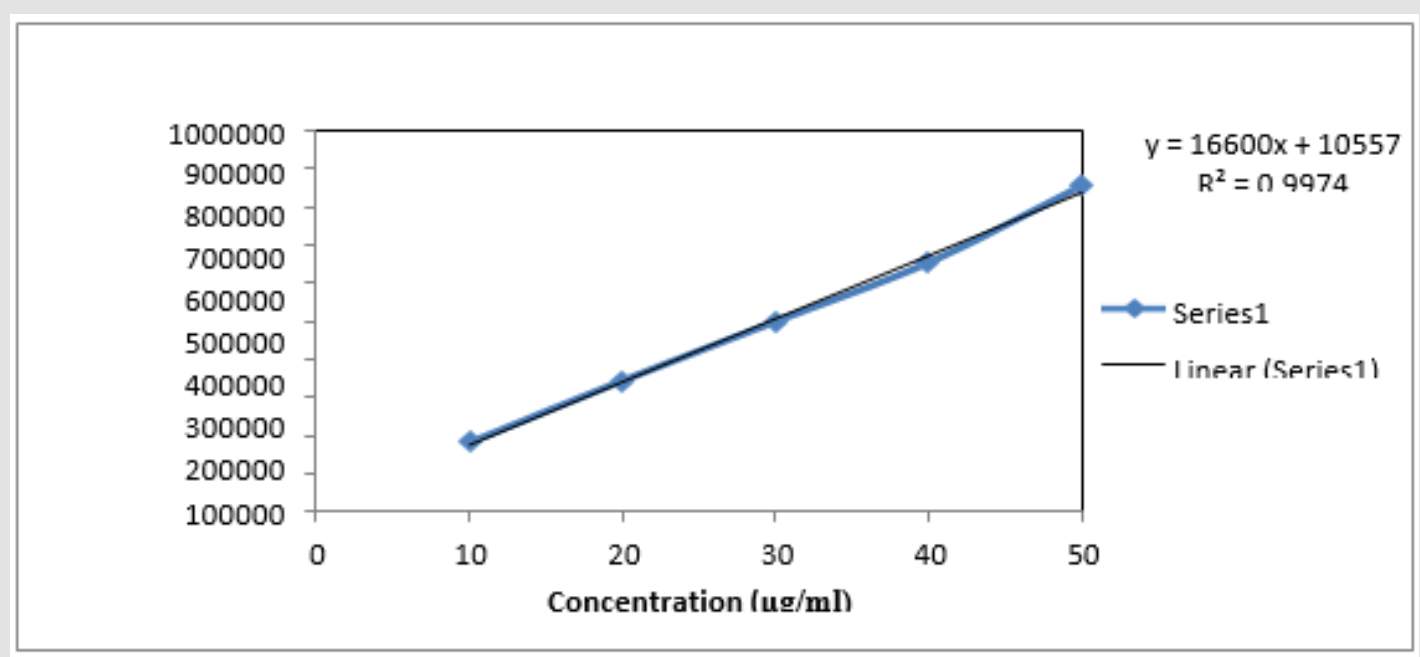

Figure 5: Plot of Linearity Curve.

Table 7: Regression data and System suitability data.

\begin{tabular}{|c|c|c|}
\hline Sr.No & Parameters & Results \\
\hline 1 & Linearity range $(\mu \mathrm{g} / \mathrm{mL})$ & 10 to $50 \mu \mathrm{g} / \mathrm{mL}$ \\
\hline 2 & Coeffi cient of determination $(\mathrm{R} 2)$ & 0.997 \\
\hline 5 & LOD & 32.91357 \\
\hline 6 & LOQ & 54.13203 \\
\hline 7 & Mean & 3243.27 \\
\hline 8 & \pm S.D. & 0.597 \\
\hline 9 & $\%$ RSD & $21,462.38$ \\
\hline 10 & Theoretical plate/ column \\
\hline 12 & Retention time & 2.772 \\
\hline 13 & Tailing factor & 1.273 \\
\hline
\end{tabular}

\section{System Suitability}

The study of chromatogram reveals that the Naftidrofuryl oxalate was well resolved hence, resolution of the same needs to be studied. The system suitability was performed by preparing the $30 \mu \mathrm{g} / \mathrm{mL}$ solution of standard Naftidrofuryl oxalate performed under optimized condition. From the observation of results, all the obtained results are in under the acceptance limit. Hence, according to acceptance criteria the system is suitable for analysis. The results for system suitability parameters are given in Table 7 and standard chromatogram is given in Figure 6. The correlation coefficient was found to be 0.997 for the drug.

\section{Accuracy}

Accuracy of proposed method was as certain on the basis of recovery studies performed by standard addition method. Percent Recovery was performed by preparing the $30 \mu \mathrm{g} / \mathrm{mL}$ solution of Standard Naftidrofuryl Oxalate. The \pm S. D and \% RSD was calculated and the results for \% Recovery is given in Table 8. 


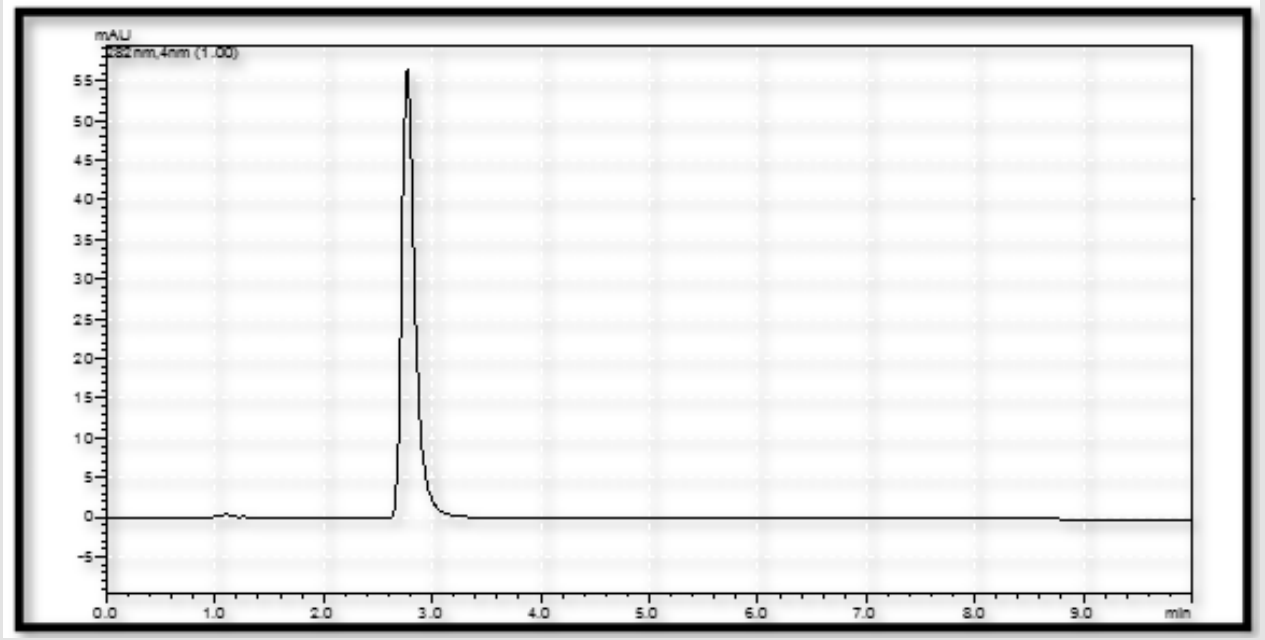

Figure 6: Chromatogram of Std NF.

Table 8: Observation and Results of Recovery Study.

\begin{tabular}{|c|c|c|}
\hline Accuracy Level & Total Amount Recovered (mg) & $\%$ Recovery \\
\hline \multirow{2}{*}{$80 \%$} & 7.9993 & 99.87 \\
\hline & 8.0539 & 100.3 \\
\hline \multirow{2}{*}{$90 \%$} & 8.9992 & 99.88 \\
\hline & 9.0126 & 100.03 \\
\hline \multirow{2}{*}{$100 \%$} & 10.0594 & 100.29 \\
\hline & 10.0675 & 100.47 \\
\hline \multirow{2}{*}{$110 \%$} & 11.1864 & 101.51 \\
\hline & 11.0045 & 99.95 \\
\hline \multirow{2}{*}{$120 \%$} & 12.1828 & 101.36 \\
\hline & 12.1287 & 100.99 \\
\hline \multicolumn{2}{|c|}{$\pm \mathrm{SD}$} & 0.581 \\
\hline \multicolumn{2}{|c|}{$\%$ RSD } & 0.58 \\
\hline
\end{tabular}

\section{Robustness}

In these study deliberate changes in the method were done i.e. Change in flow rate $(1.0 \pm 0.2 \mathrm{~mL} / \mathrm{min})$, change in mobile phase concentration (organic portion of $90 \% \pm 5 \%$ ), Change in column
(Agilent ZORBAX and ZODIAC) and change in $\mathrm{pH}$ of Buffer solution $(7.0 \pm 0.2 \mathrm{pH})$ in mobile phase. The robustness results Mean, SD and $\%$ RSD of series of measurement were found to be within limit as shown in Table 9.

Table 9: Table for summary data of Robustness results.

\begin{tabular}{|c|c|c|c|c|c|c|c|c|}
\hline \multirow{2}{*}{$\begin{array}{c}\text { Parameters } \\
\begin{array}{c}\text { Measured } \\
\text { parameters }\end{array}\end{array}$} & \multicolumn{2}{|c|}{ Change in flow rate $(\mathrm{mL} / \mathrm{Min})$} & \multicolumn{2}{|c|}{$\begin{array}{l}\text { Change in mobile phase } \\
\text { composition }\end{array}$} & \multicolumn{2}{|c|}{ Change in column } & \multicolumn{2}{|c|}{$\begin{array}{c}\text { Change in pH of buffer in } \\
\text { mobile phase }\end{array}$} \\
\hline & \pm SD & $\%$ RSD & \pm SD & $\%$ RSD & $\pm \mathrm{SD}$ & $\%$ RSD & $\pm \mathrm{SD}$ & $\% \mathrm{RSD}$ \\
\hline Rt (mL/Min) & 0.026 & 0.968 & 0.022 & 0.824 & 0.03 & 1.087 & 0.038 & 1.41 \\
\hline Area $(\mathrm{mV})$ & 563.307 & 0.103 & 2886.184 & 0.529 & 277.48 & 0.05 & 1032.169 & 0.187 \\
\hline HETP & 97.4 & 0.45 & 120.221 & 0.558 & 4.51 & 0.02 & 96.525 & 0.45 \\
\hline Tailing factor & 0.011 & 0.863 & 0.015 & 1.168 & 0.012 & 1.029 & 0.009 & 0.762 \\
\hline
\end{tabular}




\section{Ruggedness}

The studies were carried out for two different parameters i.e., Days (Intraday and Interday) and Analyst to Analyst variation. In intraday and inter-day variations, results of estimation by proposed methods were found to be varying. In inter-day study\% RSD and \% estimation was found to be increased after one day storage suggest that the NF is unstable in solution form while in intraday study, solution was found to be stable up to $3 \mathrm{~h}$. The result of estimation for Naftidrofuryl oxalate by different analysts was very much reproducible. This indicates the ruggedness of the method in the hands of different analysts. The results of Ruggedness study for the proposed method is given in Table 10.

Table 10: Results of Ruggedness study for the proposed method.

\begin{tabular}{|c|c|c|c|}
\hline \multirow[b]{2}{*}{ Conc. $(\mu \mathrm{g} / \mathrm{mL})$} & \multicolumn{3}{|c|}{ Recovery\% } \\
\hline & $\begin{array}{c}\text { Intra-day precision }(1 \mathrm{~h}, 3 \mathrm{~h} \text { and } \\
5 \mathrm{~h})\end{array}$ & $\begin{array}{c}\text { Inter-day precision }\left(1^{\text {st }}, 2^{\text {nd }} \text { and }\right. \\
\text { 3rd Day })\end{array}$ & $\begin{array}{l}\text { Analyst to analyst ruggedness } \\
\qquad(n=3)\end{array}$ \\
\hline \multirow{3}{*}{$30 \mu \mathrm{g} / \mathrm{mL}$} & 100 & 100 & 100.695 \\
\hline & 100 & 102.38 & 100.68 \\
\hline & 99.99 & 102.94 & 100.66 \\
\hline$\pm \mathrm{SD}$ & 0.002 & 1.563 & 0.016 \\
\hline$\%$ RSD & 0.002 & 1.536 & 0.016 \\
\hline
\end{tabular}

\section{Conclusion}

A validated QbD based RP-HPLC method has been developed for Naftidrofuryl oxalate utilizing "Analytical Quality by Design" (AQbD)- DOE approach. Multivariate regression analysis was successfully applied to study the main effects of three factors on the of retention time, resolution and tailing factor. BBD was employed for optimization of chromatographic conditions and used to analyse the analytical target profile by studying the interaction and quadratic effects on the factors for three selected responses. The models used for screening and optimization steps were found to be significant and confirmed method predictability. The developed method was validated for linearity, accuracy, robustness of test method, ruggedness, intermediate precision, recovery study, LOD and LOQ. The method is simple, robust, accurate and can be successfully applied to the analysis of Naftidrofuryl oxalate.

\section{Conflict of Interest}

No conflict of interest with any institution/organization.

\section{References}

1. El-Sayed MA (2013) The use of calixarene as ionophores in potentiometric ion-selective electrodes of naftidrofuryl oxalate using microsized membrane sensors for kinetic study of naftidrofuryl (NFT) degradation. European Journal of Chemistry 4:124-131.

2. (2009) British Pharmacopoeia (14 ${ }^{\text {th }}$ Edn.)., Her Majesty's Stationary office, London on behalf of MHRA, Vol. I\&amp;II, London, UK, 373.

3. Khorshid AF (2014) Chemically Modified Carbon Sensors Mixed or Single for the determination of Cardiovascular Drug Nafronyl Oxalate in Bulk, Praxilene and Human Fluids. J Biosens Bioelectron 5(153): 2.

4. Garrett ER, Barbhaiya R (1981) Prediction of Stability in Pharmaceutical Preparations XVIII: Application of High-Pressure Liquid Chromatographic Assays to Study of Nafronyl Stability and Bioanalysis. Journal of Pharmaceutical Sciences 70: 39-45.
5. Gordillo AR (1999) Lucha contra el dopaje como objetivo de salud. Adicciones 11(4): 299-310.

6. (1998) British Pharmacopoeia. Her Majesty's stationary office. London, UK 1: 2011416.

7. Waaler PJ, Mueller BW (1992) Solid-phase extraction of naftidofuryl from human plasma for high-performance liquid chromatography analysis. Int J Pharm 87: 223.

8. Walmsley LM Brodie RR, Chasseaud LF (1985) Note Determination of naftidrofuryl in human plasma by high-performance liquid chromatography with fluorescence detection. Journal of Chromatography: Biomedical Science and Applications 338: 433-437.

9. Brodie RR, Chasseaud LF, Taylor T, Hunter JO, Ciclitira PJ (1979) Determination of naftidrofuryl in the plasma of humans by highperformance liquid chromatography. J Chromatogr Biomed Appl 164: 534.

10. Yu C, Zhang H, Hong Y, Cui G, Xia F (1997) RP-HPLC fluorimetry of naftidrofuryl in serum. Zhongguo Yiyao Gongye Zazhi 28: 311.

11. Beyer KH, Hildebrand M (1982) Naftidrofuryl (Dusodril) Possible uses of gas chromatography and high-pressure liquid chromatography for analysis. Deutsche Apotheker Zeitun 122: 1709.

12. Cruces-Blanco C, Segura Carretero A, Fernandez Sanchez JF, Fernandez Gutierrez A (2000) Facile and selective determination of the cerebral vasodilator nafronyl in a commercial formulation by heavy atom induced room temperature phosphorimetry. J Pharm Biomed Anal 23: 845.

13. Munoz de la Pena A, Espinosa Mansilla A, Murillo Pulgarin JA, Alanon Molina A, Fernandez Lopez P (1998) Determination of nafronyl in pharmaceutical preparations by means of stopped-flow micellarstabilized room temperature phosphorescence. Analyst 123: 2285

14. Segura Carretero A, Cruces Blanco C, Canabate B, Diaz JF, Fernandez Sanchez A Fernandez Gutierrez (2000) Heavy-atom induced roomtemperature phosphorescence: A straightforward methodology for the determination of organic compounds in solution. Anal Chim Act 417: 19

15. Murillo Pulgarin JA, Alanon Molina A, Fernandez Lopez P (1999) Phosphorimetric determination of nafronyl in pharmaceutical preparations. Anal Chim Acta 382: 77. 
16. Ionescu MS, Badea V, Baiulescu GE, Cosofret VV (1986) Nafronyl ionselective membrane electrodes and their use in pharmaceutical analysis. Talanta 33: 101.

17. Belal TS, Barary MH, Sabry SM, Ibrahim MEA (2009) Kinetic spectropho- tometric analysis of naftidrofuryl oxalate and vincamine in pharmaceutical preparations using alkaline potassium permanganate. J Food Drug Anal 17: 415.

18. Sabry SM, Belal TS, Barary MH, Ibrahim MEA (2009) Spectrophotometric, spectrofluorimetric and voltammetric analyses of naftidrofuryl oxalate in its tablets. Int J Biomed Sci 5: 283.

19. Abbas SS, Zaazaa HE, El-Ghobashy MR, Fayez YM, Fattah SA (2012) Stability Indicating Methods for Determination of Naftidrofuryl Oxalate: Analytical Chemistry An Indian Journal 11: 329-334.

20. Garrett ER, Barbhaiya R (1981) Prediction of stability in pharmaceutical preparations XVIII: application of high-pressure liquid chromatographic assays to study of nafronyl stability and bioanalysis. J Pharm Sci 70: 39.

21. Moffat AC, Osselton MD, Widdop B (2004) Clark's Analysis of Drugs and Poisons ( $3^{\text {rd }}$ Edn.)., The Pharmaceutical Press, London, UK, pp. 1311 1312

22. Alhakeem MA, Ghica MV, Pîrvu CD, Anuța V, Popa L (2019) Analytical Quality by Design with the Lifecycle Approach: A Modern Epitome for Analytical Method Development. Acta Medica Marisiensis 65: 37-44.

23. Peraman R, Bhadraya K, Padmanabha Reddy Y (2015) Analytical quality by design: a tool for regulatory flexibility and robust analytics. International journal of Analytical Chemistry.

24. Yadav NK, Raghuvanshi A, Sharma G, Beg S, Katare OP, et al. (2016) QbDbased development and validation of a stability-indicating HPLC method for estimating ketoprofen in bulk drug and proniosomal vesicular system. J Chromatogr Sci 54: 377-389.

25. Garg NK, Sharma G, Singh B, Nirbhavane P, Katare OP (2015) Quality by design (QbD)-based development and optimization of a simple, robust RP-HPLC method for the estimation of methotrexate. J Liq Chromatogr Relat Technol 38: 1629-1637.

26. Thakur D, Kaur A, Sharma S (2017) Application of QbD based approach in method development of RP-HPLC for simultaneous estimation of antidiabetic drugs in pharmaceutical dosage form. J Pharm Investig 47 229-239.

\section{ISSN: 2574-1241}

DOI: 10.26717/BJSTR.2021.40.006447

Krishna R Gupta. Biomed J Sci \& Tech Res

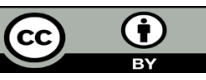

This work is licensed under Creative

Commons Attribution 4.0 License

Submission Link: https://biomedres.us/submit-manuscript.php
27. Bhusnure OG, Shinde NG, Gholve SB, Giram PS (2015) QbD approach for analytical method development of anti-pschotic drug, Pharm. Lett 7: 6270.

28. Elkhoudary MM, AbdelSalam RA, Hadad GM (2016) Development and optimization of HPLC analysis of metronidazole, diloxanide, spiramycin and cliquinol in pharmaceutical dosage forms using experimental design. J Chromatogr Sci 54: 1701-1712.

29. Bhutani H, Kurmi M, Singh S, Beg S, Singh B (2017) Quality by design (QbD) in analytical sciences: an overview. Quality Assurance 46: 71-75.

30. Ganorkar AV, Gupta KR. Analytical Quality by Design: A Mini Review. Biomedical Journal of Scientific \& Technical Research 1(6): 1555-1559.

31. Fukuda IM, Pinto CF, Moreira CD, Saviano AM, Lourenço FR (2018) Design of Experiments (DoE) applied to pharmaceutical and analytical Quality by Design (QbD). Brazilian Journal of Pharmaceutical Sciences 54(SPE).

32. Rakic T, Kasagic-Vujanovic I, Jovanovic M, Jancic-Stojanovic B, Ivanovic D (2014) Comparison of full factorial design, central composite design, and box-behnken design in chromatographic method development for the determination of fluconazole and its impurities. Analytical letters 47(8): 1334-1347.

33. Tak JW, Gupta B, Thapa RK, Woo KB, Kim SY, et al. (2017) Preparation and optimization of immediate release/sustained release bilayered tablets of loxoprofen using Box-Behnken design. AAPS Pharm SciTech 18: $1125-1134$.

34. Ganorkar SB, Shirkhedkar AA (2017) Design of experiments in liquid chromatography (HPLC) analysis of pharmaceuticals: Analytics, applications, implications and future prospects. Reviews in Analytical Chemistry 36: 1-43.

35. Ferreira SC, Bruns RE, Ferreira HS, Matos GD, David JM, et al. (2007) Box-Behnken design: an alternative for the optimization of analytical methods. Analytica chimica acta 597: 179-186.

36. Box GE, Behnken DW (1960) Some new three level designs for the study of quantitative variables. Technometrics 2: 455-475.

37.(2007) Validation of compendial Procedures, United State Pharmacopoeia USP-NF 2007, Pharmacopoeial Convention Inc., General chapter 5: 1225 .

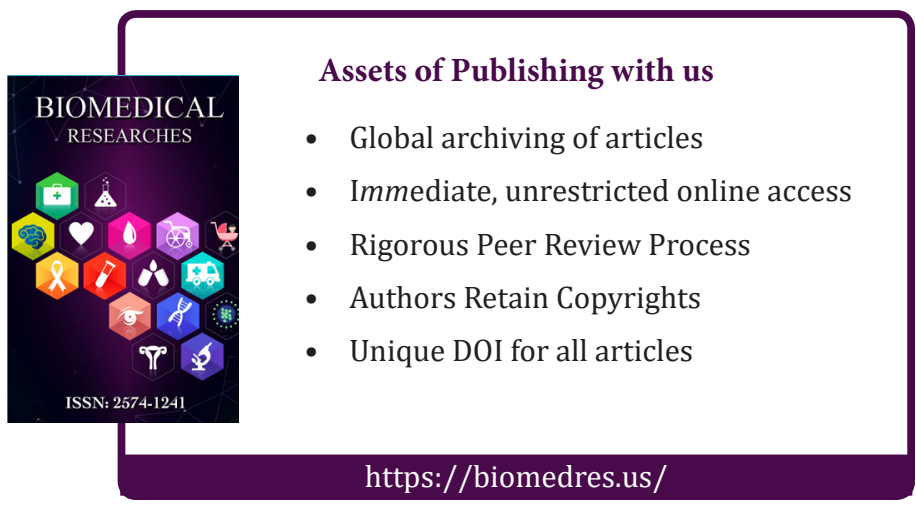

